\title{
Letter to Editor: "Artificial Intelligence, Machine Learning, Deep Learning and Big Data Analytics for Resource Optimization in Surgery"
}

\author{
Vikesh Agrawal $^{1,2}$ (D) Dhananjaya Sharma ${ }^{2} \cdot$ Sanjay Kumar Yadav ${ }^{2}$ \\ Received: 3 September 2020 / Accepted: 14 October 2020 / Published online: 21 October 2020 \\ (C) Association of Surgeons of India 2020
}

Dear Editor,

Health care delivery in the pandemic is heavily disrupted. There are high stakes and economic implications are huge especially in more vulnerable low and middle-income group countries (LMICs). It is even more imperative now that we optimize our resources. Artificial intelligence (AI) and its exploits should now be requisitioned. Two subsets of AI are machine learning (ML) which in turn enables deep learning (DL). Big data are analyzed [1]. Such tasks are complex and will require yeoman efforts both on the parts individuals and governments. The respective state and central governments will provide regulatory sanctions. Preparations into big data analysis, machine learning leading to deep learning is likely to save resources. The current pandemic has amply shown this and should prompt us to invest in AI. Efforts and investment in deep learning should be translational in resource allocation and resource triage even during normal settings. We have written an iterative algorithm that should convince the stakeholders to invest in this modality (Fig. 1).

Vikesh Agrawal

drvikeshagrawal@gmail.com

Dhananjaya Sharma

dhanshar@gmail.com

Sanjay Kumar Yadav

sky1508@gmail.com

1 Pediatric Surgery Division, Department of Surgery, Netaji Subhash Chandra Bose Government Medical College, Nagpur Road, Jabalpur 482003, India

2 Department of Surgery, Netaji Subhash Chandra Bose Government Medical College, Nagpur Road, Jabalpur 482003, India 
Fig. 1 Resource-optimization algorithm based on four-level risk stratification for elective surgical services during pandemic and the proposed deep learning module. PPE- Personal Protective Equipment, AGP- Aerosol Generating Procedure, ICUIntensive Care Unit

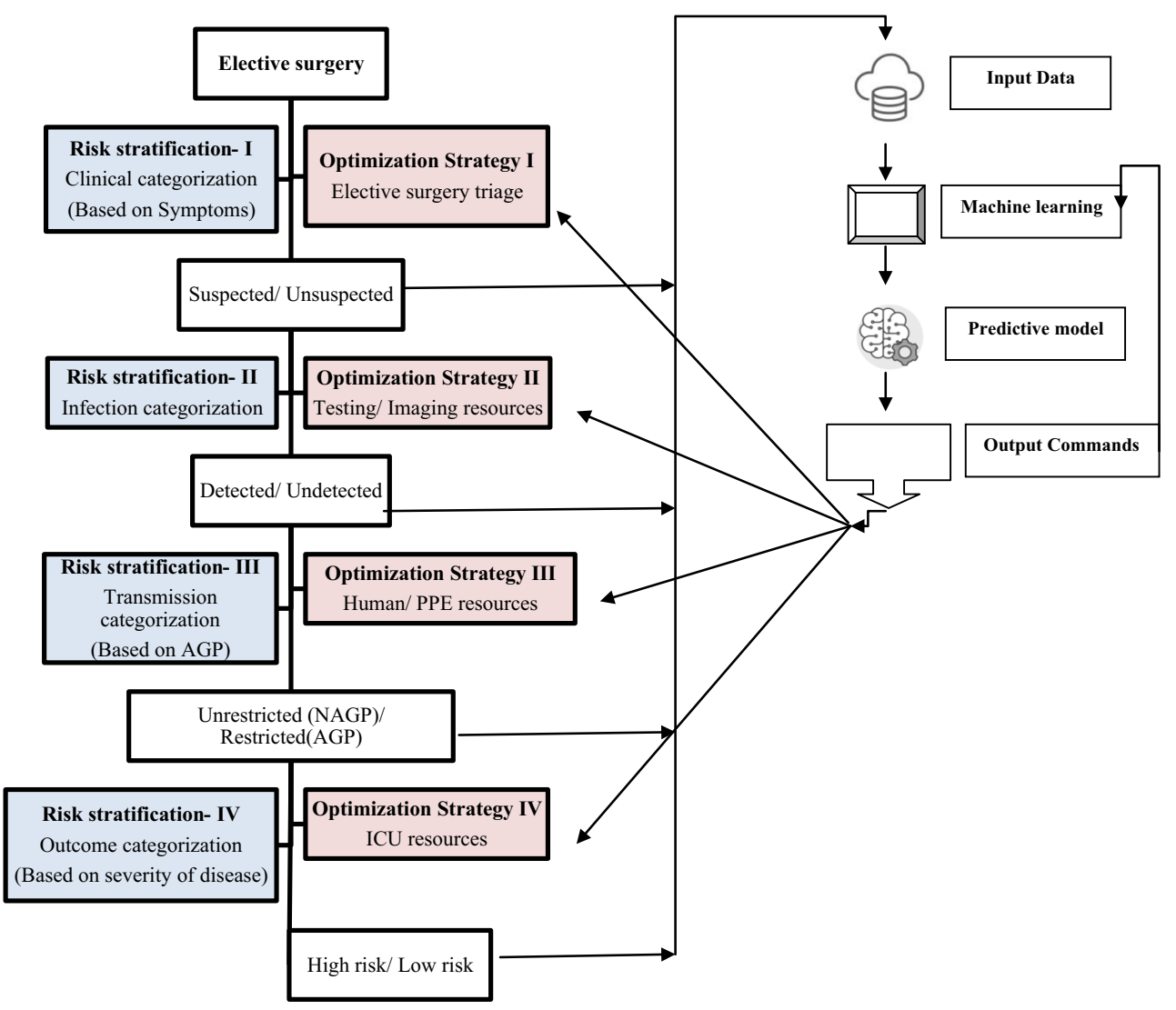

\section{Compliance with Ethical Standards}

Conflict of Interest The authors declare that they have no conflict of interest.

\section{Reference}

1. Al Knawy B, Adil M, Crooks G, Rhee K, Bates D, Jokhdar H, Klag M, Lee U, Mokdad AH, Schaper L, Al Hazme R, Al Khathaami AM, Abduljawad J (2020) The Riyadh Declaration: the role of digital health in fighting pandemics. Lancet S0140-6736(20):3197831974. https://doi.org/10.1016/S0140-6736(20)31978-4

Publisher's Note Springer Nature remains neutral with regard to jurisdictional claims in published maps and institutional affiliations. 